\title{
Evaluation of landfill gas plant siting problem: a multi-criteria approach
}

\author{
Desmond Eseoghene Ighravwe ${ }^{1^{*}(\mathbb{C}}$, Damilola Elizabeth Babatunde ${ }^{2 \oplus}$ \\ ${ }^{1}$ Department of Mechanical and Biomedical Engineering, Bells University of Technology, Ota, Nigeria \\ ${ }^{2}$ Department of Chemical Engineering, Covenant University, Ota, Nigeria
}

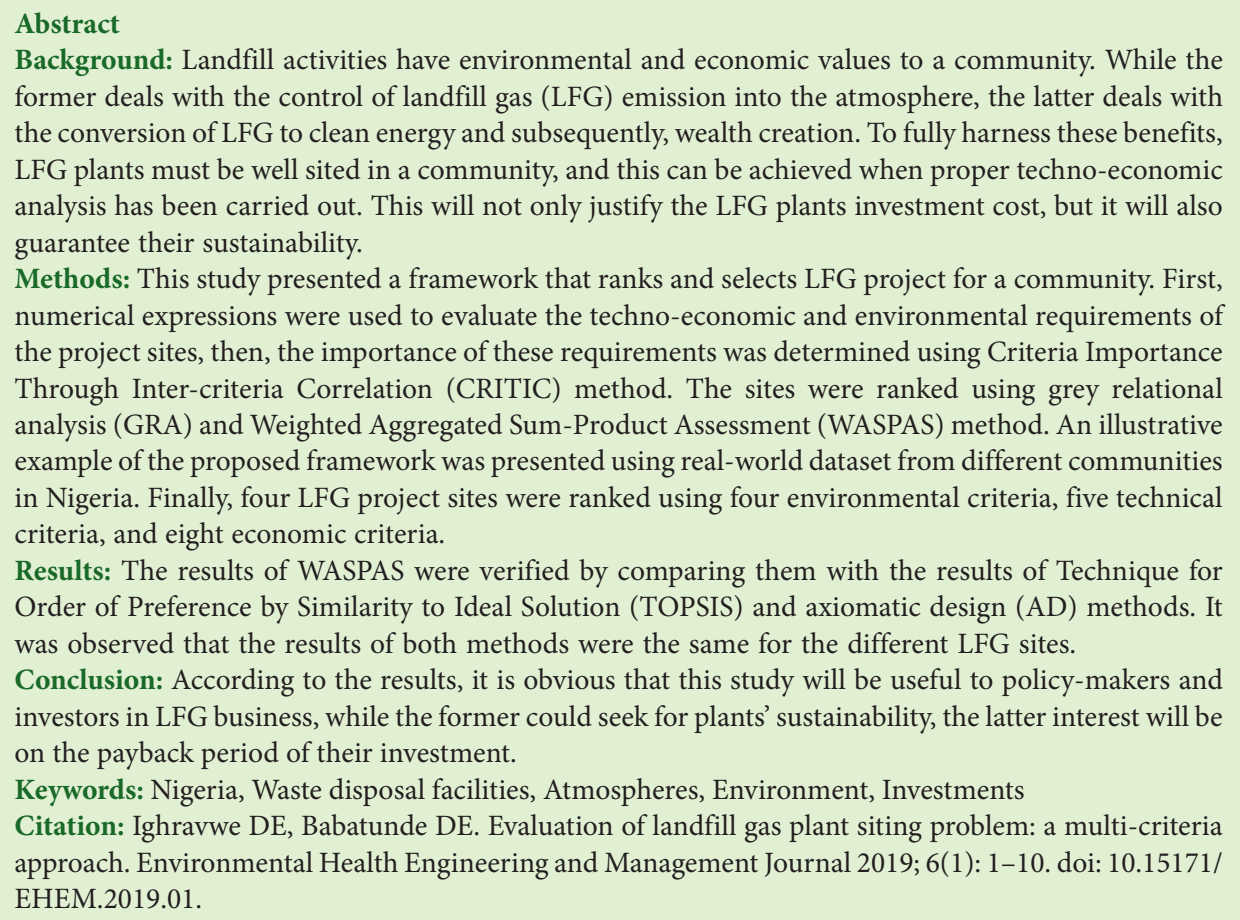
former deals with the control of landfill gas (LFG) emission into the atmosphere, the latter deals with the conversion of LFG to clean energy and subsequently, wealth creation. To fully harness these benefits, LFG plants must be well sited in a community, and this can be achieved when proper techno-economic analysis has been carried out. This will not only justify the LFG plants investment cost, but it will also guarantee their sustainability.

Methods: This study presented a framework that ranks and selects LFG project for a community. First, numerical expressions were used to evaluate the techno-economic and environmental requirements of the project sites, then, the importance of these requirements was determined using Criteria Importance Through Inter-criteria Correlation (CRITIC) method. The sites were ranked using grey relational analysis (GRA) and Weighted Aggregated Sum-Product Assessment (WASPAS) method. An illustrative example of the proposed framework was presented using real-world dataset from different communities in Nigeria. Finally, four LFG project sites were ranked using four environmental criteria, five technical criteria, and eight economic criteria.

Results: The results of WASPAS were verified by comparing them with the results of Technique for Order of Preference by Similarity to Ideal Solution (TOPSIS) and axiomatic design (AD) methods. It was observed that the results of both methods were the same for the different LFG sites.

Conclusion: According to the results, it is obvious that this study will be useful to policy-makers and investors in LFG business, while the former could seek for plants' sustainability, the latter interest will be on the payback period of their investment.

Keywords: Nigeria, Waste disposal facilities, Atmospheres, Environment, Investments Citation: Ighravwe DE, Babatunde DE. Evaluation of landfill gas plant siting problem: a multi-criteria approach. Environmental Health Engineering and Management Journal 2019; 6(1): 1-10. doi: 10.15171/ EHEM.2019.01.

\section{Article History:}

Received: 3 October 2018

Accepted: 1 January 2019

ePublished: 27 January 2019

\section{Introduction}

The current population explosion has not only increased the demand for energy (1), but it has also increased the demand for clean environment and waste management, therefore, making policy on energy and waste management can be considered as a conjoined twins $(2,3)$. Energy experts and researchers believe that wastes should not only be seen as a raw material for petrochemical industry, but it must also be considered as raw materials for energy plants - biomass and landfill gas (LFG) plants (4). Discussions on the latter are still on-going and a lot of people believe that with adequate information, the nightmare of waste management will become history, and that compensation of energy shortage will be experienced as another benefit of co-analysis of waste and energy problems. To truly understand this analysis, waste and energy generation should be jointly considered (5).

Promoting the need for simultaneous consideration of waste and energy is an attempt to further enhance the discussion on renewable energy. As the potential of using waste to generate energy is increasing, it will open investment opportunity across different communities and simultaneously, address energy shortage problems. In some cases, it is possible to hybridize energy from LFG with other renewable energy sources (solar and wind). For this reason, energy experts will move from energy generation problem to energy management problem. Unfortunately, most discussions on energy problems is still at energy generation level, especially in developing countries, where population growth is continually putting more pressure on energy (hydro or thermal) plants. Countries experiencing this challenge do not have any 
option to diversify energy sources in their communities. Any attempt to deal with this problem requires the efforts of all stakeholders: governments, private investors, and citizens.

Energy diversification not only reduces dependence on a single source of energy, but it also covers how energy is transported and supplied to a community. In short, this concept is a multi-phase problem. It requires a real understanding of the interrelationships among energy generation, supply, and transportation. Yet, the components must be analyzed independently before any meaningful effort be made to couple any findings on this matter. While the need for an encompassing approach for energy diversification is acknowledged, this study still emphasizes the need to include biogas in the discussion of energy development in developing countries. The reason is that the issue of energy generation must be properly addressed before any contributions on its supply or transport having a meaningful impact. For example, the site of an LFG plant must be determined before any discussion on how to supply or transport gas from such a plant.

To some people, LFG plant location problem is a technical and environmental problem, while others who are knowledgeable about sustainability pillar, believe that social factors must be considered in the analysis of this problem. According to studies on the other kinds of energy plants siting, it can be said that the latter school of thought has a case on why an LFG plant siting solution must be a sustainable solution. With the current efforts on LFG analysis, the relationship among these criteria can be easily established using multi-criteria tools including Technique for Order of Preference by Similarity to Ideal Solution (TOPSIS), axiomatic design (AD), VIsekriterijumska optimizacija i KOmpromisno Resenje (VIKOR), and Preference Ranking Organization Method for Enrichment of Evaluations (PROMETHEE) methods. Aragonés-Beltrán et al (6) and Tavares et al (7) used multi-criteria tools to investigate plant siting problems. According to their studies, it is possible to replicate the same idea to address LFG plant problems (siting and sizing). But the study will be selected based on the data structures that are considered by decisionmakers for LFG. Also, when criteria values are specified it affects the choice of a multi-criteria tool for a problem. Unfortunately, LFG literature has sparsely discussed the use of these tools for its decision-making problems. In the coming years, it is believed that this problem will be solved by the growing interest among researchers in LFG study $(8,9)$. In view of this, the present study contributes to the expected discussion on multi-criteria and LFG. The principal motivation for this contribution is the need to present a framework that can be used to make decision about LFG plant siting. Currently, energy literature has focused attention on the type of energy plant siting, while the issue of LFG plant siting has been rarely considered. To our knowledge, there is no literature on the use of technoeconomic and environmental criteria to solve the problem of LFG plant siting. Solving this problem will guide policymakers and provide investors with relevant information on the establishment of LFG plant. Thus, the aim of this study was to present a framework for LFG plant siting problem. In the proposed framework, environmental, technical, and economic requirements are considered as parameters for LFG plant siting - a multi-criteria approach $(10,11)$. Waste generation is an inevitable result of living, increasing population, urbanization, industrialization, and economic growth. Therefore, different types of waste management strategies have been evolved for the management of waste. Landfilling is a predominant method adopted for waste disposal and its operation may controlled or uncontrolled in different countries (12-14). Aesthetic challenges, groundwater contamination, and air pollution are known to be associated with landfilling; leachate and biogas are the main products of anaerobic degradation of organic matters in a landfill (15). Methane forms the larger percentage of the biogas formed and when the biogas is not properly controlled, landfills become a major contributor to non- $\mathrm{CO}_{2}$ greenhouse gas (GHG) emissions and these emissions have negative impacts on the environment and neighbouring residents. Although the age and origin of landfilled waste are major factors influencing the composition and quantity of $\operatorname{LFG}(15,16)$, LFG is generally characterized by high calorific value so that an amount of methane can be stored to serve as a viable renewable alternative to the dwindling fossil fuels (17-19) and also, helps preserve the environment through reduction of non- $\mathrm{CO}_{2}$ greenhouse gases emissions in the environment.

Adequate understanding of landfill processes leads to the improvement of generation and sales of LFG in order to meet energy needs. Access to deposited waste and several landfill parameters also play important roles. Details of the processes involved in LFG generation have been broadly discussed in literature (14-16). The degradation of the organic portion of landfill wastes generally involves acetogenesis, methanogenesis, and oxidation phases. Each of these phases has an effect on the landfill environment, leachate composition, and biogas composition. The rates of LFG and methane generation have been identified as one of the parameters for LFG site selection and are related to the leachate characteristics. Leachate characteristics such as $\mathrm{pH}$, chemical oxygen demand (COD), and biological oxygen demand (BOD) help predicate the rates of LFG and methane generation (20). The prediction accuracy level of LFG generation goes a long way to determine the viability and profitability of the generating plant.

Various models have been developed to predict the rates of LFG and methane generation $(8,9)$, however, a model that fully accounts for all factors affecting the generation process is not identified yet. Environmental impact is also a major factor influencing the selection of LFG plants site. 
Topography, the effect of the site on vegetation and fauna, the direction and speed of local wind, odour and dust emissions with respect to the neighbourhood, the risk of fire outbreak or explosion as a result of the gas generation, access route, and the effect of the plant on traffic are some of the environmental criteria for the selection of LFG plants site. Political acceptance of the intended LFG plant site and ownership of the required land are the other factors that can be used to determine the location of LFG plant. The level of acceptance may vary from one community to another and the type of land ownership of a LFG plant will have a significant effect on the cost. Hydrology, is another significant criterion to be considered when siting an LFG plant.

In order to prevent the release of wastes into streams, groundwaters, rivers, drinking water sources and other major water bodies, safe distance of the site from these waters bodies would be a goal to be achieved. Economic implications such as the cost of access to landfill which generates the gas to be processed in the LFG plant, cost of a required facility, cost of manpower, and cost of transport are also calculated for sustainability. Other criteria include geology, the location of residential settlements, the location of industrial areas, and climate characteristics. The geology, among other criteria, is related to the soil types, parent materials, capacities, and migration of leachate. Some environmental regulations prohibit the location of LFG plants close to residential and industrial areas mainly because of the nature of the major sources of raw materials for the plant, the effluents from the plant, and hazards characterizing the operation of the plant. Inappropriate landfill and LFG generation site is more likely to have negative environmental, economic, and ecological impacts on the host community. The selection of a site for landfill waste disposal and subsequent landfill LFG production plant using conventional methods usually involves combining several data layers, and is time-consuming and error-prone. This awareness has led to the development of properly designed environmental information systems to facilitate the flow of environmental information from data sources to stakeholders and also to transform organization and management of spatial data for the enhanced environmental decision-making process. Combining well-developed environmental information systems with various multi-criteria decision-making methods has led to significant advances in decision making on the landfill site. As nearness to the sources of raw materials is crucial for siting of any plant, significant advances in decision making on the selection of landfill site may be expected extend to LFG plant location. Meeting environmental risk management objectives having its basis from environmental regulations, has been the focus of most decision-making support tool for landfill sites (21). Chabuk et al (22) identified two suitable sites which could accommodate solid waste from 2020 to 2030 in Al-Hashimiyah Qadhaa, Babylon, and Iraq using combined multi-criteria decision-making (MCDM) and geographical information system (GIS) applications. Analytical hierarchy process (AHP) and analytical network process (ANP) have been applied in a study on landfill site selection (23). In a region of Iran, integration of fuzzy logic and ANP has been found to be more suitable in defining landfill site than when applied distinctly (24). Nikkhah et al (25) employed hybrid LFG emissions modelling (LandGEM) and life cycle assessment (LCA) to determine the right period of biogas production from Saravan landfill in Northern Iran. Gorsevski et al (26) evaluated the suitability of a landfill site in the Polog Region, Macedonia, using a GIS-based multi-criteria decision analysis approach (GIS-MCDA). Considering the depth of groundwater, distance from the surface level to groundwater, access routes, residential areas, industries, power transmission lines, flood-proneness, faults, slope, and distance between gardens and agricultural lands, Yousefi et al (11) integrated GIS and Analytical Hierarchical Process (AHP) to facilitate landfill site selection.

In a way similar to landfill sites, well-established MCDA can be used to select LFG plant site where a generation of LFG is a criterion. The present study aimed to rank LFG sites using techno-economic and environmental factors.

\section{Materials and Methods}

In an attempt to solve the current problem, several multicriteria tools including criteria importance through intercriteria correlation (CRITIC) - weight determination, grey relational analysis (GRA) - criteria aggregation, weighted aggregated sum-product assessment (WASPAS) - rank determination, and TOPSIS - rank determination were considered in this study. The proposed framework to use these tools in the present study is shown in Figure 1. In this study, TOPSIS method was used to verify the performance of WASPAS because studies have shown that the latter one can be used to check the performance of the former $(27,28)$.

\section{CRITIC method}

In the alternatives evaluation, the performance of multicriteria tools, such as TOPSIS, VIKOR, PROMETHEE, and others, depends on the importance of criteria. To determine the importance of the evaluation criteria, difference variety of the same multi-criteria tool has been reported in literature. Ighravwe and Oke (29) used fuzzy entropy method to determine the maintenance strategy criteria when applying WASPAS method, while Ghorshi Nezhad et al (30) combined SWARA and WASPAS for solving a mall location problem. Despite the unique attributes of these tools, most of them are often considered as the normalized values of the criteria values - entropy method. Normalization is required to make all the criteria in a decision-matrix to be within the same range ( 0 and 1$)$ (Eq. 1 and 2). During this process, consideration is given 


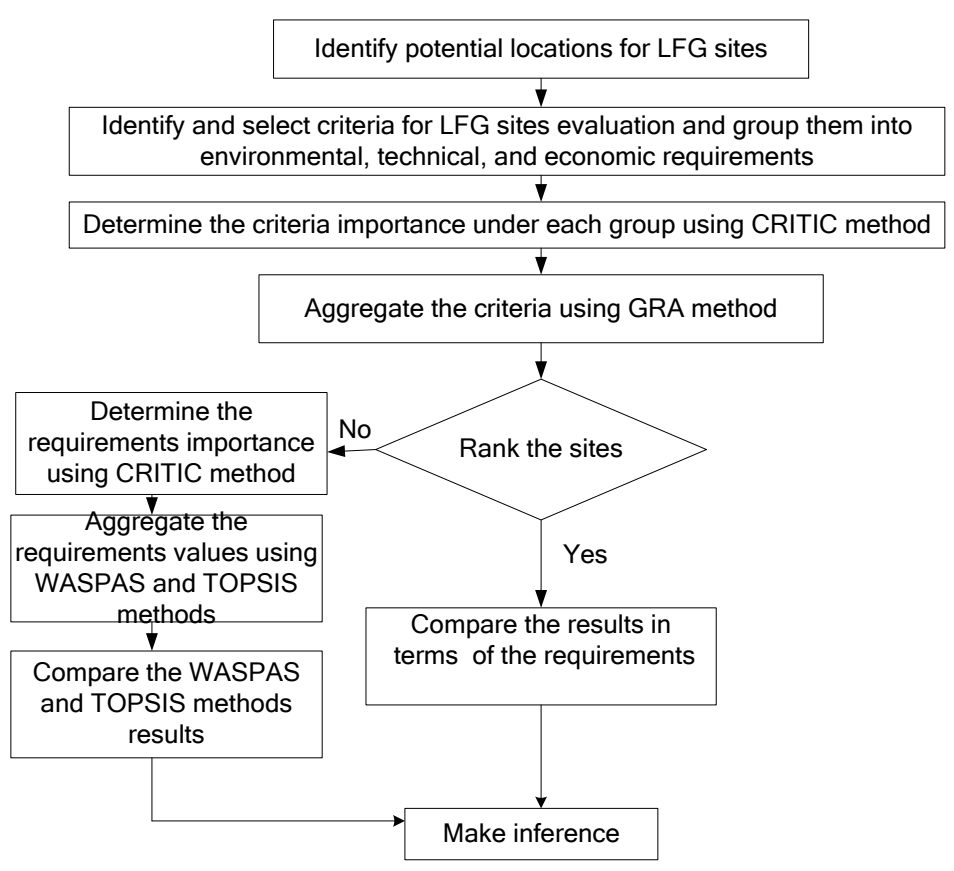

Figure 1. The proposed framework for LFG plant siting.

to the criteria orientation - cost or benefit. While Eq. (1) represents the normalization expression for the costoriented criteria, Eq. (2) represents the expression for the benefit-oriented criteria.

$$
\begin{aligned}
& x_{i}(k)=\frac{y_{i}(k)-\min _{i} y_{i}(k)}{\max _{i} y_{i}(k)-\min _{i} y_{i}(k)} \\
& x_{i}(k)=\frac{\max _{i} y_{i}(k)-y_{i}(k)}{\max _{i} y_{i}(k)-\min _{i} y_{i}(k)}
\end{aligned}
$$

While most of the multi-criteria tools use experts' judgements to determine a criterion weight, CRITIC method uses criteria values to determine criteria weights. With this attribute, CRITIC method eliminates experts' judgments when evaluating criteria importance. Instead, it uses weight importance that is data-dependent. To achieve this, standard deviation (Eq. 3) and criterion coefficient (Eq. 4) values of the data in a decision-matrix are considered. When the results of Eq. (3) and (4) are combined, a criterion information measure is generated Eq. (5).

$$
\sigma_{j}=\sqrt{\frac{\sum_{i=1}^{m}\left(x_{i j}-\bar{x}_{j}\right)^{2}}{m}}
$$

$$
r_{j k}=\frac{\sum_{i=1}^{m}\left(x_{i j}-\bar{x}_{j}\right)\left(x_{i k}-\bar{x}_{k}\right)}{\sqrt{\sum_{i=1}^{m}\left(x_{i j}-\bar{x}_{j}\right)^{2} \sum_{i=1}^{m}\left(x_{i k}-\bar{x}_{k}\right)^{2}}}
$$

$$
H_{j}=\sigma_{j} \sum_{k=1}^{K}\left(1-r_{j k}\right)
$$

With the information contents, a criterion's importance is determined using Eq. (6).

$$
w_{j}=\frac{H_{j}}{\sum_{j=1}^{n} H_{j}}
$$

Grey relational analysis

In a multi-criteria analysis, several tools have been proposed and applied including TOPSIS, VIKOR, AD, GRA, and others-, by researchers to address a wide range of decision-making problems. The choice of a tool is often based on the problem structure and the tool's characteristics, for example, where design requirements are the major factors, AD has been proved to be a useful tool for such problems. In the case of a TOPSIS method, its application is useful where issues such as criteria weights, best and worst solutions are considered by decisionmakers. While in most of the tools, the importance of criteria should be considered, AD and GRA can be used to make a decision with or without considering the criteria importance $(31,32)$. Now, the question is that when should $\mathrm{AD}$ or GRA be used to solve a problem. This question is best answered by considering the characteristics of these tools and the problem structure. For the former, the problem structure must specify design requirements, while the latter cannot be used to solve a problem that has design requirements. Thus, GRA is selected as a multicriteria tool for solving the current problem $(33,34)$, This is because it does not consider design requirements or criteria. 
While GRA has found wide applications in machining domain, its application has been found to be useful for other engineering and non-engineering problems. However, it is progressively making headways in other human endeavours such as maintenance planning (29). While we look forward to its extensive application in energy study, the present study considered this tool as a potential decision-making tool for LFG plant site ranking. Like other decision-making tools, this method arranges data in a matrix using the relationship between criteria and alternatives (Eq. 7).

$D=\left[\begin{array}{llll}y_{11} & y_{12} & \ldots & y_{1 n} \\ y_{21} & y_{22} & \ldots & y_{2 n} \\ \vdots & \vdots & \ldots & \vdots \\ y_{1 m} & y_{2 m} & \ldots & y_{m n}\end{array}\right]$

Before using information in the matrix to make a decision, it is subjected to a data normalization process - data pre-processing. Based on the normalized comparison sequence, grey relational coefficients are determined (Eq. $8)$. For this purpose, an identification coefficient $(\zeta)$ and target sequence should be determined (Eq. 9).

$$
\Delta\left(x_{o}(k), x_{i}(k)\right)=\frac{\Delta \min +\xi \Delta \max }{\Delta_{o i}(k)+\xi \Delta \max }
$$

$\Delta_{o i}(k)=\left|x_{o}(k)-x_{i}(k)\right|$

Using the results obtained from Eq. (8), the GRA for alternatives is evaluated. But the importance of the criteria may be required (Eq. 10). The results obtained from this equation provide a basis for ranking alternatives. The alternatives with the highest and least GRA are considered as the most and least preferred alternatives.

$x_{i}=\frac{1}{K} \sum_{k=1}^{K} \Delta\left(x_{o}(k), x_{i}(k)\right) w_{k}$

\section{WAPAS}

While in this study a GRA method was used to combine intra-related criteria, inter-related criteria are combined using WASPAS method. This method is devoid of complex mathematics that is associated with other multicriteria methods such as AD, VIKOR, PROMETHEE, and more. While common and system areas are required for
AD method, VIKOR method requires regret and utility indices, and PROMETHE method requires positive and negative flows values to rank alternatives. On the other hand, WASPAS method requires only the weighted sum and weighted product values to determine alternative ranks.

This method, like any other multi-criteria method, uses normalized values to determine weighted sum, weighted product, and WASPAS values for alternatives. To normalize the techno-economic and environment values from the GRA process, Eq. (11) is used. Unlike Eq. (1) and (2) that considered criteria orientation (i.e., cost or benefit), Eq. (11) does not consider criteria orientation. Based on the alternatives' normalized values, some scholars have been able to hybridize WASPAS method. And this is done using different multi-criteria tools to determine the criteria importance. To determine the criteria importance, AHP, ANP, SWARA and others have been considered by scholars (Table 1).

$y_{i j}=\frac{x_{i j}}{\sqrt{\sum_{j=1}^{n}\left\{x_{i j}\right\}^{2}}}$

In the present study, CRITIC method was used to determine the criteria importance. Alternatives' weighted sum and product values are expressed as Eq. (12) and (13), respectively. Mathematically, the relationship between the weighted sum and weighted product is expressed as Eq. (14). This new equation determines the alternatives' WASPAS values, and it is controlled using a contribution coefficient. This factor makes it possible to simulate the alternatives' ranks.

$$
\begin{aligned}
& Q_{i}^{1}=\sum_{j=1}^{n} x_{i j} w_{j} \\
& Q_{i}^{2}=\sum_{j=1}^{n} x_{i j}{ }^{w_{j}} \\
& Q_{i}=\lambda Q_{i}^{1}+(1-\lambda) Q_{i}^{2}
\end{aligned}
$$

\section{TOPSIS}

Despite the improvements in multi-criteria tools, -TOPSIS method ease of application, and best and worst solutions consideration continues to increase its acceptance among

Table 1. Selected tools for determination of WASPAS criteria weight

\begin{tabular}{lll}
\hline Author(s) & Tool & Study \\
\hline Lashgari et al (35) & Quantitative strategic planning matrix & Healthcare management \\
Vafaeipour et al (36) & SWARA & Energy management \\
Ghorshi Nezhad et al (30) & SWARA & Real estate \\
Turskis et al (37) & Fuzzy-AHP & Construction management \\
Ighravwe and Oke (29) & Fuzzy-entropy method & Maintenance management \\
Sremac et al (38) & SWARA & Logistic management \\
Alam et al (39) & Fuzzy AHP & Service providers - ITC \\
\hline
\end{tabular}


researchers (40). Because of this, literature in different disciplines, such as engineering, management, science and others, show the results that are generated using TOPSIS $(28,40)$. While this sound interesting, there is a need to jump-start to apply TOPSIS in LFG analysis because other energy domains (e.g. energy mix, storage, and pricing) have enjoyed the application of TOPSIS more than LFG domain. To push this argument forwards, this study presents a standard TOPSIS method as an alternative tool to select an LFG plant site - a verification tool. This tool includes three main steps to make a decision on the most preferred alternative for decision-making problems: normalization, distance evaluation, and closeness coefficient measurement.

\section{Normalization}

Similar to the above-mentioned multi-criteria tools (GRA and WASPAS), TOPSIS also normalized dataset before it can be used to implement its other basic steps (Eq. 1 and 2). In addition to data normalisation the weighted normalized values of the datasets are also considered in the implementation of TOPSIS method (Eq. 15).

$$
r_{i j}=x_{i j} w_{j}
$$

\section{Distance evaluation}

Using a weighted normalized decision-matrix, the ideal and non-ideal distance for the alternatives are generated it can only be achieved after defining the ideal and nonideal solutions for the criteria. To do this, the maximum and minimum values of criteria in a weighted normalized decision-matrix are considered as Eq. (16) and (17). After determining these values, an alternative ideal distance from the criteria ideal solutions is expressed as Eq. (18), while an alternative non-ideal solution is expressed as Eq. (19).

$$
\begin{aligned}
& d_{j}^{+}=\max _{j} r_{i j} \quad \forall i \\
& d_{j}^{-}=\min _{j} r_{i j} \quad \forall i \\
& D_{i}^{+}=\sum_{j=1}^{n}\left(r_{i j}-d_{j}^{+}\right)^{2} \quad \forall i
\end{aligned}
$$

$$
D_{i}^{-}=\sum_{j=1}^{n}\left(r_{i j}-d_{j}^{-}\right)^{2} \quad \forall i
$$

\section{Closeness coefficient}

Based on the distance ideal and non-ideal alternatives, their closeness coefficients are determined using Eq. (20). The closeness coefficient values serve as a basis of ranking alternative solutions. The alternatives with the highest and lowest closeness coefficient values are considered as the most and least preferred alternatives.

$C C_{i}=\frac{D_{i}^{-}}{D_{i}^{+}+D_{i}^{-}}$

Case study

The proposed framework was applied using four communities in Nigeria as a potential site for a LFG project. Detailed descriptions of the communities are summarized in Table 2. Ranking of the communities in Table 2 with respect to LFG plant siting is based on the four environmental criteria: total lifetime of methane collected and used (E11), GHG value of total lifetime of methane utilized (E12), total lifetime of $\mathrm{CO}_{2}$ generated from avoided energy (E13), and total lifetime of carbon from generated from avoided energy (E14). Also, five technical criteria were considered in the ranking process: projected total methane $\left(\mathrm{m}^{3} / \mathrm{yr}\right), \mathrm{T} 21$; methane generation potential $(\mathrm{Gg} / \mathrm{yr}), \mathrm{T} 22$; methane generation potential of waste $\left(\mathrm{ft}^{3} / \mathrm{ton}\right), \mathrm{T} 23$; volume of oxygen (\%), T24; and degradable organic carbon (DOC), T25. The economic implications of using any of the communities as an LFG plant site were also considered: payback period, C31; internal rate of returns, C32; minimum average electricity price, C33; maximum average electricity price; annual operating costs (\$), C35; total installation cost, C36; net present value (NPV), C37; and minimum electricity price, C38.

The values for the environmental, technical, and economic requirements for the different communities were obtained from literature (Table 3) (41). It should be noted that the payback period and internal rate of returns were determined using electricity price of $\$ 0.2$ per $\mathrm{kWh}$.

Table 2. Landfill sites description (41)

\begin{tabular}{ll}
\hline Landfill Site & Description \\
\hline Afofuna (A1) & $\begin{array}{l}\text { It started its operations in } 1979 \text { and its capacity is approximately } 10 \text { hectares. While paper and textile materials (19.4\%) are rare in this } \\
\text { site, it contained a high percentage of wood/straw wastes. }\end{array}$ \\
The area of this site is approximately 16 hectares and it was commissioned in 1989. This site has a high percentage of food wastes \\
when compared with other types of wastes (53.51\%) - wood/straw, paper and textile, and among others wastes - and wood/straw \\
wastes are the least types of wastes in this site (1.9\%). \\
Ajakanga (A3) & $\begin{array}{l}\text { It occupies an area of approximately } 10 \text { hectares and it was commissioned in 1996. This site contained a high percentage of wood/ } \\
\text { straw wastes (28.40\%), while food waste is the least type of waste in this site (21.80\%). }\end{array}$ \\
Awotan (A4) & $\begin{array}{l}\text { This site started operations in } 1998 \text { and its size is approximately } 25 \text { hectares. At Awotan site, food wastes (36.67\%) is the highest type } \\
\text { of waste, while wood/straw wastes are the least type of waste (25.70\%). }\end{array}$ \\
\hline
\end{tabular}


Table 3. Values of the evaluation criteria (41)

\begin{tabular}{|c|c|c|c|c|c|}
\hline Criteria & Preferred & A1 & A2 & A3 & A4 \\
\hline \multicolumn{6}{|c|}{ Environmental Criteria } \\
\hline E11 & Max & 183 & 247 & 324 & 212 \\
\hline E12 & Max & 0.055 & 0.074 & 0.977 & 0.0638 \\
\hline E13 & Max & 0.006 & 0.00808 & 0.0106 & 0.00694 \\
\hline E14 & Max & 0.0016 & 0.002 & 0.0029 & 0.00189 \\
\hline \multicolumn{6}{|c|}{ Technical Criteria } \\
\hline T21 & Max & 539547.1 & 2150296 & 617267.7 & 720433 \\
\hline T22 & Max & 1.42 & 2.56 & 2.71 & 1.616 \\
\hline T23 & Max & 2158 & 3051 & 2246 & 2171 \\
\hline T24 & Max & 37.31 & 36.7 & 36.54 & 36.89 \\
\hline T25 & Max & 0.245 & 0.234 & 0.255 & 0.235 \\
\hline \multicolumn{6}{|c|}{ Economic Criteria } \\
\hline C31 & Min & 15 & 15 & 15 & 14 \\
\hline C32 & Max & 10 & 11 & 11 & 12 \\
\hline C32 & Max & 0.2 & 0.17 & 0.14 & 0.19 \\
\hline C34 & Max & 0.24 & 0.2 & 0.17 & 0.22 \\
\hline C35 & Min & 42655 & 48728 & 53246 & 45811 \\
\hline C36 & Min & 765308 & 734895 & 819254 & 689133 \\
\hline C37 & Max & 6338 & 21826 & 14990 & 32644 \\
\hline C38 & Min & 0.21 & 0.18 & 0.15 & 0.2 \\
\hline
\end{tabular}

\section{Results}

Table 3 shows that the cost-oriented criteria were normalized using Eq. (1), while the benefit-oriented criteria were normalized using Eq. (2). Using the CRITIC method (Section 3.2), the importance of the criteria was determined (Table 4).

In order to apply the GRA method (Section 3.2), $\Delta \max$ and $\Delta \min$ were set at 1 and 0 , respectively. Also, the value of $\xi$ and $x_{i}(p)$ were obtained to be 0.5 and 1 , respectively (31). With these values, the results of Tables 3 and 4 were combined using a GRA approach and the obtained results are presented in Table 5.

To determine the requirements' importance in the proposed model, CRITIC method was used. The results from Table 5 were considered in this process and the results obtained are presented in Table 6 .

In the evaluation process, the WASPAS method (Section 3.2) was used to combine the results obtained from Tables 5 and 6 . And, weighted additive and weighted products values of the LFG plant sites were determined (Table 7). The values were then combined using different $\lambda$ values (Table 8).

The TOPSIS method (Section 3.4) was used to rank the LFG plant sites (Table 5). This was achieved by combining the data obtained from Table 5 with those from Table 6 requirements' importance. But the results obtained from Table 5 were first normalized before being combined with the requirements' importance and obtaining the normalized weighted values for the LFG sites (Table 9).

\section{Discussion}

According to the results of Table 3, the CRITIC method ranked E12 as the most important environmental criterion,
Table 4. Criteria importance

\begin{tabular}{|c|c|c|c|c|}
\hline Criteria & $r_{j k}$ & $\sigma_{j}$ & $H_{j}$ & $w_{j}$ \\
\hline \multicolumn{5}{|c|}{ Environmental Criteria } \\
\hline E11 & 1.1055 & 0.1232 & 0.1362 & 0.1393 \\
\hline E12 & 1.2204 & 0.4641 & 0.5664 & 0.5791 \\
\hline E13 & 1.1044 & 0.1229 & 0.1357 & 0.1387 \\
\hline E14 & 1.0727 & 0.1303 & 0.1397 & 0.1429 \\
\hline \multicolumn{5}{|c|}{ Technical Criteria } \\
\hline T21 & 4.4763 & 0.3176 & 1.4217 & 0.5370 \\
\hline T22 & 4.5473 & 0.1517 & 0.6896 & 0.2605 \\
\hline T23 & 4.3325 & 0.0886 & 0.3837 & 0.1450 \\
\hline T24 & 6.8424 & 0.0045 & 0.0308 & 0.0117 \\
\hline T25 & 5.9849 & 0.0203 & 0.1215 & 0.0459 \\
\hline \multicolumn{5}{|c|}{ Economic Criteria } \\
\hline C31 & 9.6372 & 0.0169 & 0.1633 & 0.0253 \\
\hline C32 & 8.7155 & 0.0370 & 0.3228 & 0.0500 \\
\hline C33 & 8.1786 & 0.0750 & 0.6130 & 0.0950 \\
\hline C34 & 8.2433 & 0.0714 & 0.5886 & 0.0912 \\
\hline C35 & 9.7501 & 0.0471 & 0.4594 & 0.0712 \\
\hline C36 & 9.8765 & 0.0362 & 0.3578 & 0.0555 \\
\hline C37 & 8.5484 & 0.2615 & 2.2350 & 0.3464 \\
\hline C38 & 8.1786 & 0.2094 & 1.7127 & 0.2654 \\
\hline
\end{tabular}

while E11 is the least important environmental criterion. This method identified T21 and T24 as the most and least important technical criteria, respectively (Table 4). Also, this method identified C37 and C31 as the most and least important economic criteria, respectively (Table 4). When this method was used to rank the LFG requirements (technical, economic, and environmental), it was observed that the environmental and economic requirements were 
Table 5. GRA outputs

\begin{tabular}{lllll}
\hline Requirements & A1 & A2 & A3 & A4 \\
\hline Environmental & 0.0703 & 0.1399 & 0.1676 & 0.0223 \\
Technical & 0.0871 & 0.1418 & 0.0784 & 0.1201 \\
Economic & 0.0658 & 0.0840 & 0.0705 & 0.0866 \\
\hline
\end{tabular}

Table 6. The requirements' importance

\begin{tabular}{lcccc}
\hline Requirements & $\boldsymbol{r}_{\boldsymbol{j} \boldsymbol{k}}$ & $\boldsymbol{\sigma}_{\boldsymbol{j}}$ & $\boldsymbol{H}_{\boldsymbol{j}}$ & $\boldsymbol{W}_{\boldsymbol{j}}$ \\
\hline Environmental & 3.4527 & 0.0660 & 0.2279 & 0.7120 \\
Technical & 2.2998 & 0.0294 & 0.0676 & 0.2112 \\
Economic & 2.4177 & 0.0102 & 0.0246 & 0.0768 \\
\hline
\end{tabular}

Table 7. Weighted sum and weighted product results of the LFG sites

\begin{tabular}{lcccc}
\hline & A1 & A2 & A3 & A4 \\
\hline Weighted sum & 0.0735 & 0.1360 & 0.1413 & 0.0479 \\
Weighted product & 0.0732 & 0.1349 & 0.1336 & 0.0354 \\
\hline
\end{tabular}

Table 8. WASPAS outputs for various $\lambda$ values

\begin{tabular}{lllll}
\hline $\boldsymbol{\Lambda}$ & A1 & A2 & A3 & A4 \\
\hline 0.1 & 0.0732 & 0.1350 & 0.1343 & 0.0366 \\
0.2 & 0.0732 & 0.1351 & 0.1351 & 0.0379 \\
0.3 & 0.0733 & 0.1352 & 0.1359 & 0.0391 \\
0.4 & 0.0733 & 0.1353 & 0.1366 & 0.0404 \\
0.5 & 0.0733 & 0.1354 & 0.1374 & 0.0416 \\
0.6 & 0.0734 & 0.1355 & 0.1382 & 0.0429 \\
0.7 & 0.0734 & 0.1356 & 0.1390 & 0.0441 \\
0.8 & 0.0734 & 0.1358 & 0.1397 & 0.0454 \\
0.9 & 0.0735 & 0.1359 & 0.1405 & 0.0467 \\
\hline
\end{tabular}

Table 9. Summary of TOPSIS outputs

\begin{tabular}{|c|c|c|c|c|}
\hline & A1 & A2 & A3 & A4 \\
\hline \multicolumn{5}{|c|}{ Normalized Values } \\
\hline Environmental & 0.3050 & 0.6071 & 0.7274 & 0.0969 \\
\hline Technical & 0.3966 & 0.6453 & 0.3567 & 0.5466 \\
\hline Economic & 0.4256 & 0.5436 & 0.4564 & 0.5608 \\
\hline \multicolumn{5}{|c|}{ Weighted Normalized Values } \\
\hline Environmental & 0.2172 & 0.4322 & 0.5179 & 0.0690 \\
\hline Technical & 0.0838 & 0.1363 & 0.0753 & 0.1154 \\
\hline Economic & 0.0327 & 0.0417 & 0.0351 & 0.0431 \\
\hline \multicolumn{5}{|c|}{ TOPSIS Outputs } \\
\hline Ideal distance & 0.0933 & 0.0073 & 0.0038 & 0.2019 \\
\hline Non-ideal distance & 0.0220 & 0.1357 & 0.2015 & 0.0017 \\
\hline Closeness coefficients & 0.1910 & 0.9487 & 0.9816 & 0.0084 \\
\hline
\end{tabular}

the most and least important requirements, respectively. From the foregoing, the contributions of E12 and T21 to the ranking of the LFG sites from environmental and technical perspectives were approximately $57.91 \%$ and $53.70 \%$, respectively. In addition, the results of Table 4 show that the contribution of C37 to the selection of a LFG site from the economic perspective was approximately
$34.64 \%$.

In terms of the environmental requirement, $\mathrm{A} 3$ and $\mathrm{A} 4$ were ranked as the most and least preferred LFG plant sites, respectively. These ranks are not the same as those of the technical requirements. The latter ranked the best and least preferred LFG plant sites as A2 and A3, respectively. Also, the results of the environmental and economic requirements were not the same. The latter ranked the most and least preferred LFG sites as A4 and A1, respectively. To synergize these discrepancies in the results, the weighted sum and weighted products results were examined. According to Table 7, it can be inferred that the most preferred LFG site from the weighted sum results was $\mathrm{A} 3$, while the weighted product results identified A2 as the most preferred LFG site.

The WASPAS method identified A2 as the most preferred site for the LFG project when $\lambda=0.1$. However, when $\lambda$ was increased to $0.2, \mathrm{~A} 2$ and $\mathrm{A} 3$ emerged as the most preferred sites, respectively. In order to break this tie, the value of $\lambda$ was increased to 0.3 and A3 was identified as the most preferred site. Considering other $\lambda$ values in Table 8, A3 was the most preferred site. It was also revealed that when $\lambda$ value ranges between 0.3 and 0.9 , the ranking of the site was the same- A3, A2, A1, and A4. Also, for the various $\lambda$ values, the ranking of $\mathrm{A} 1$ and $\mathrm{A} 4$ as the third and fourth landfill sites, respectively was the same. Furthermore, the ranking of the WASPAS method when $\lambda$ ranges between 0.3 and 0.9 was similar to that of the TOPSIS method.

\section{Conclusion}

The results obtained from studies on LFG have been used to present a decision support framework for solving the problem of LFG plant siting. First, this study discussed the need to examine the viability of LFG sites for a sound LFG investment decision under techno-economic and environmental requirements. Another issue that this study is the need for a multi-criteria analysis of LFG siting problem in order to ensure about the LFG plant sustainability. Therefore, this study presented a framework ranking LFG plant sites using a GRA method. It also evaluated the LFG criteria importance. In terms of the environmental and technical requirements, four and five criteria were considered, respectively, while the importance of eight economic LFG criteria were determined in this study. These criteria were analyzed using the CRITIC method and the results obtained were used to implement the GRA method. Hereafter, the proposed model applicability was verified based on the real-world datasets from four communities in Nigeria. In this case-control study, four LFG plant sites and their suitability for a LFG project were analyzed from environmental, technical, and economic perspectives. By considering these perspectives, no consistency in the results was observed. For instance, A3, A2, and A4 were ranked as the most preferred LFG plant sites from the environmental, technical, and economic perspectives, 
respectively. Likewise, there were discrepancies among the least preferred LFG sites from various perspectives: environmental - A4, technical - A3, economic - A1. In order to resolve these discrepancies, the LFG plant sites results were aggregated using WASPAS method. It was observed that the most and least preferred LFG plant sites were A3 and A4, respectively. These results were verified with TOPSIS method, and it was observed that the results of WASPAS and TOPSIS methods generated the same ranks.

Despite the insights on LFG presented in this study, this study has some limitations that if addressed, its sustainability robustness as a decision support tool for the LFG plant investment will be enhanced. One of the limitations is related to the selection of gas turbine for LFG plants under a multi-objective scenario. Also, this study did not justify the reasons for the selection of the criteria that were used to rank the LFG plant sites. Addressing these issues will not only improve the LFG establishment decision, but it will also affect the decision on the size of an LFG plant for a community. Furthermore, human requirements for LFG plant was not included in the proposed framework. Technically, the operational needs of LFG must not only consider material requirements, but it must also look at technical know-how availability where a LFG plant should be sited. This is necessary in order to reduce a plant's operational cost and its sustainability. Considering these issues before arriving at a LFG plant siting decision, will guarantee the optimal benefits from an LFG plant.

Despite the benefits of plant sustainability and operational cost reduction, optimal energy-mix, environmental sustainability, and energy poverty reduction are among other benefits of a stable LFG plant siting model. It is worth mentioning that some of these benefits depend on data quality and reliability that are used to implement an LFG model. One way to guarantee data quality and reliability is to generate requisite data from other models before using them to run an LFG model. For instance, the optimal unit cost for an LFG plant can be determined using an optimization model, while a predictive model such as a neural network can be used to forecast the LFG demand for a community. Unfortunately, there is sparse information on the use of such models for the above-mentioned objectives. Therefore, researchers and practitioners are recommended to explore these knowledge gaps. Another area that is open for research is the issue of optimal sizing and siting of an LFG plant. A natural solution to this problem could be the application of non-linear optimization models. Such models consider plant size and LFG demand as continuous variables, and the total number of LFG plant sites as an integer variable.

\section{Acknowledgements}

The authors would like to gratitude the reviewers for their insightful comments that helped the authors improve the quality of this article.

\section{Ethical issues}

The authors certify that all data collected during the study are as stated in the manuscript, and no data from the study has been or will be published separately elsewhere.

\section{Competing interests}

The authors declare that they have no conflict of interests.

\section{Authors' contribution}

All authors contributed in data collection, analysis, and interpretation. All authors critically reviewed, refined, and approved the manuscript.

\section{References}

1. Acar C. A comprehensive evaluation of energy storage options for better sustainability. International Journal of Energy Research 2018; 42(12): 3732-46. doi: 10.1002/er.4102.

2. Ayodele TR, Ogunjuyigbe AS, Alao MA. Life cycle assessment of waste-to-energy (WtE) technologies for electricity generation using municipal solid waste in Nigeria. Appl Energy 2017; 201: 200-18. doi: 10.1016/j.apenergy.2017.05.097.

3. Moya D, Aldas C, Lopez G, Kaparaju P. Municipal solid waste as a valuable renewable energy resource: a worldwide opportunity of energy recovery by using waste-to-energy technologies. Energy Procedia 2017; 134: 286-95. doi: 10.1016/j.egypro.2017.09.618.

4. Dace E, Blumberga D, Kuplais G, Bozko L, Khabdullina Z, Khabdullin A. Optimization of landfill gas use in municipal solid waste landfills in Latvia. Energy Procedia 2015; 72: 293 9. doi: 10.1016/j.egypro.2015.06.042.

5. Sims RE, Rogner HH, Gregory K. Carbon emission and mitigation cost comparisons between fossil fuel, nuclear and renewable energy resources for electricity generation. Energy Policy 2003; 31(13): 1315-26. doi: 10.1016/S03014215(02)00192-1.

6. Aragonés-Beltrán P, Pastor-Ferrando JP, Garcia-Garcia F, Pascual-Agullo A. An analytic network process approach for siting a municipal solid waste plant in the Metropolitan Area of Valencia (Spain). J Environ Manage 2010; 91(5): 1071-86. doi: 10.1016/j.jenvman.2009.12.007.

7. Tavares G, Zsigraiova Z, Semiao V. Multi-criteria GISbased siting of an incineration plant for municipal solid waste. Waste Manag 2011; 31(9-10): 1960-72. doi: 10.1016/j. wasman.2011.04.013.

8. Thompson S, Sawyer J, Bonam R, Valdivia JE. Building a better methane generation model: validating models with methane recovery rates from 35 Canadian landfills. Waste Manag 2009; 29(7): 2085-91. doi: 10.1016/j.wasman.2009.02.004.

9. Kamalan H, Sabour M, Shariatmadari N. A review on available landfill gas models. Journal of Environmental Science and Technology 2011; 4(2): 79-92. doi: 10.3923/jest.2011.79.92.

10. Yedla S, Parikh JK. Economic evaluation of a landfill system with gas recovery for municipal solid waste management: a case study. Int J Environ Pollut 2001; 15(4): 433-47. doi: 10.1504/IJEP.2001.004834.

11. Yousefi H, Javadzadeh Z, Noorollahi Y, Yousefi-Sahzabi A. Landfill Site selection using a multi-criteria decision-making method: a case study of the Salafcheghan special economic zone, Iran. Sustainability 2018; 10(4):1107. doi: 10.3390/ su10041107. 
12. Barros RM, Tiago Filho GL, da Silva TR. The electric energy potential of landfill biogas in Brazil. Energy Policy 2014; 65: 150-64. doi: 10.1016/j.enpol.2013.10.028.

13. dos Santos IF, Barros RM, Tiago Filho GL. Economic study on LFG energy projects in function of the number of generators. Sustain Cities Soc 2018; 41: 587-600. doi: 10.1016/j. scs.2018.04.029.

14. Njoku PO, Odiyo JO, Durowoju OS, Edokpayi JN. A review of landfill gas generation and utilisation in Africa. Open Environmental Sciences 2018; 10: 1-15. doi: $10.2174 / 1876325101810010001$.

15. Asgari MJ, Safavi K, Mortazaeinezahad F. Landfill biogas production process. International Proceedings of Chemical, Biological and Environmental Engineering (IPCBEE) 2011; 9:208-12.

16. Markovic J, Stevovic S. The process of creation and analysis of the landfill gas from the landfill in the region of Pchinja. Journal on Processing and Energy in Agriculture 2016; 20(2): 63-8.

17. Themelis NJ, Ulloa PA. Methane generation in landfills. Renewable Energy 2007; 32(7): 1243-57. doi: 10.1016/j. renene.2006.04.020.

18. Amini HR, Reinhart DR. Regional prediction of long-term landfill gas to energy potential. Waste Manag 2011; 31(9-10): 2020-6. doi: 10.1016/j.wasman.2011.05.010.

19. Schneider DR, Kirac M, Hublin A. Cost-effectiveness of GHG emission reduction measures and energy recovery from municipal waste in Croatia. Energy 2012; 48(1): 203-11. doi: 10.1016/j.energy.2012.02.008.

20. Emkes H, Coulon F, Wagland S. A decision support tool for landfill methane generation and gas collection. Waste Manag 2015; 43: 307-18. doi: 10.1016/j.wasman.2015.07.003.

21. Laner D, Crest M, Scharff H, Morris JW, Barlaz MA. A review of approaches for the long-term management of municipal solid waste landfills. Waste Manag 2012; 32(3): 498-512. doi: 10.1016/j.wasman.2011.11.010.

22. Chabuk A, Al-Ansari N, Hussain HM, Knutsson S, Pusch $\mathrm{R}$, Laue J. Combining GIS applications and method of multi-criteria decision-making (AHP) for landfill siting in Al-Hashimiyah Qadhaa, Babylon, Iraq. Sustainability 2017; 9(11): 1932. doi: 10.3390/su9111932.

23. Bottero M, Comino E, Riggio V. Application of the analytic hierarchy process and the analytic network process for the assessment of different wastewater treatment systems. Environ Model Softw 2011; 26(10): 1211-24. doi: 10.1016/j. envsoft.2011.04.002.

24. Isalou AA, Zamani V, Shahmoradi B, Alizadeh H. Landfill site selection using integrated fuzzy logic and analytic network process (F-ANP). Environ Earth Sci 2013; 68(6): 1745-55. doi: 10.1007/s12665-012-1865-y.

25. Nikkhah A, Khojastehpour M, Abbaspour-Fard MH. Hybrid landfill gas emissions modeling and life cycle assessment for determining the appropriate period to install biogas system. J Clean Prod 2018; 185: 772-80. doi: 10.1016/j. jclepro.2018.03.080.

26. Gorsevski PV, Donevska KR, Mitrovski CD, Frizado JP. Integrating multi-criteria evaluation techniques with geographic information systems for landfill site selection: a case study using ordered weighted average. Waste Manag 2012; 32(2): 287-96. doi: 10.1016/j.wasman.2011.09.023.

27. Keshavarz Ghorabaee M, Amiri M, Zavadskas EK, Turskis Z, Antucheviciene J. A new hybrid simulation-based assignment approach for evaluating airlines with multiple service quality criteria. Journal of Air Transport Management 2017; 63: 45-
60. doi: 10.1016/j.jairtraman.2017.05.008.

28. Deveci M, Canitez F, Gokasar I. WASPAS and TOPSIS based interval type-2 fuzzy MCDM method for a selection of a car sharing station. Sustain Cities Soc 2018; 41: 777-91. doi: 10.1016/j.scs.2018.05.034.

29. Ighravwe DE, Oke SA. A multi-hierarchical framework for ranking maintenance sustainability strategies using PROMETHEE and fuzzy entropy methods. Journal of Building Pathology and Rehabilitation 2017; 2(1): 9. doi: 10.1007/s41024-017-0028-7.

30. Ghorshi Nezhad MR, Hashemkhani Zolfani S, Moztarzadeh F, Zavadskas EK, Bahrami M. Planning the priority of high tech industries based on SWARA-WASPAS methodology: the case of the nanotechnology industry in Iran. Economic Research-Ekonomska Istrazivanja 2015; 28(1): 1111-37. doi: 10.1080/1331677X.2015.1102404.

31. Lin ST, Horng SJ, Lee BH, Fan P, Pan Y, Lai JL, et al. Application of grey-relational analysis to find the most suitable watermarking scheme. International Journal of Innovative Computing, Information and Control 2011; 7(9): 5389-401.

32. Khandekar AV, Chakraborty S. Selection of material handling equipment using fuzzy axiomatic design principles. Informatica 2015; 26(2): 259-82. doi: 10.15388/ Informatica.2015.48.

33. Kuo Y, Yang T, Huang GW. The use of a grey-based Taguchi method for optimizing multi-response simulation problems. Engineering Optimization 2008; 40(6): 517-28. doi: $10.1080 / 03052150701857645$.

34. Hasani H, Akhavan Tabatabaei S, Amiri G. Grey relational analysis to determine the optimum process parameters for open-end spinning yarns. J Eng Fiber Fabr 2012; 7(2): 81-6. doi: $10.1177 / 155892501200700212$.

35. Lashgari S, Antucheviciene J, Delavari A, Kheirkhah O. Using QSPM and WASPAS methods for determining outsourcing strategies. Journal of Business Economics and Management 2014; 15(4): 729-43. doi: 10.3846/16111699.2014.908789.

36. Vafaeipour M, Hashemkhani Zolfani S, Morshed Varzandeh MH, Derakhti A, Keshavarz Eshkalag M. Assessment of regions priority for implementation of solar projects in Iran: New application of a hybrid multi-criteria decision making approach. Energy Convers Manag 2014; 86: 653-63. doi: 10.1016/j.enconman.2014.05.083.

37. Turskis Z, Zavadskas EK, Antucheviciene J, Kosareva N. A hybrid model based on fuzzy AHP and fuzzy WASPAS for construction site selection. Int J Comput Commun Control 2015; 10(6): 873-88.

38. Sremac S, Stevic Z, Pamucar D, Arsic M, Matic B. Evaluation of a third-party logistics (3PL) provider using a rough SWARAWASPAS model based on a new rough dombi aggregator. Symmetry 2018; 10(8): 1-25. doi: 10.3390/sym10080305.

39. Alam KA, Ahmed R, Butt FS, Kim SG, Ko KM. An uncertainty-aware integrated fuzzy AHP-WASPAS model to evaluate public cloud computing services. Procedia Comput Sci 2018; 130: 504-9. doi: 10.1016/j.procs.2018.04.068.

40. Ighravwe DE, Babatunde MO. Selection of a mini-grid business model for developing countries using CRITICTOPSIS with interval type-2 fuzzy sets. Decision Science Letters 2018; 7(4): 427-42. doi: 10.5267/j.dsl.2018.1.004.

41. Environmental Protection Agency (EPA). Landfill recovery and use in Nigeria (pre-feasibility studies of using LFGE). Washington, DC: EPA; 2010. 